\title{
Move it or lose it: interspecific variation in risk response of pond-breeding anurans
}

\author{
Philip Matich ${ }^{\text {Corresp., 1, } 2}$, Christopher M Schalk ${ }^{3}$ \\ ${ }^{1}$ Department of Marine Biology, Texas A\&M University - Galveston, Galveston, Texas, United States \\ ${ }^{2}$ Texas Research Institute for Environmental Studies, Sam Houston State University, Huntsville, Texas, United States \\ 3 Arthur Temple College of Forestry and Agriculture, Stephen F. Austin State University, Nacogdoches, Texas, United States \\ Corresponding Author: Philip Matich \\ Email address: pmatich@tamug.edu
}

Changes in behavior are often the proximate response of animals to human disturbance, with variability in tolerance levels leading some species to exhibit striking shifts in life history, fitness, and/or survival. Thus, elucidating the effects of disturbance on animal behavior, and how this varies among taxonomically similar species with inherently different behaviors and life histories is of value for management and conservation. We evaluated the risk response of three anuran species - southern leopard frog (Lithobates sphenocephalus), Blanchard's cricket frog (Acris blanchardi), and green tree frog (Hyla cinerea) - to determine how differences in microhabitat use (arboreal vs ground-dwelling) and body size (small vs medium) may play a role in response to a potential threat within a human-altered subtropical forest. Each species responded to risk with both flight and freeze behaviors, however behaviors were species- and context-specific. As distance to cover increased, southern leopard frogs increased freezing behavior, green tree frogs decreased freezing behavior, and Blanchard's cricket frogs increased flight response. The propensity of green tree frogs to use the canopy of vegetation as refugia, and the small body size of Blanchard's cricket frogs likely led to greater flight response as distance to cover increased, whereas innate reliance on camouflage among southern leopard frogs may place them at greater risk to landscaping, agricultural, and transportation practices in open terrain. As such, arboreal and small-bodied species may inherently be better suited in human altered-landscapes compared to larger, ground-dwelling species. As land-use change continues to modify habitats, understanding how species respond to changes in their environment continues to be of importance, particularly in ecosystems where humanwildlife interactions are expected to increase in frequency. 
1 Move it or lose it: interspecific variation in risk response of pond-breeding anurans

2

3 Philip Matich ${ }^{1,2}$, Christopher M. Schalk ${ }^{3}$

4

$5{ }^{1}$ Department of Marine Biology, Texas A \& M University at Galveston, Galveston, TX, USA

$6{ }^{2}$ Texas Research Institute for Environmental Studies, Sam Houston State University, Huntsville,

7 TX, USA

$8{ }^{3}$ Arthur Temple College of Forestry and Agriculture, Stephen F. Austin State University,

9 Nacogdoches, TX, USA

10

11

12

13

14

15

16

17

18

19

20 Corresponding Author:

21 Philip Matich

221001 Texas Clipper Road, Galveston, TX 77553, USA

23 Email address: pmatich@tamug.edu 


\section{Abstract}

25 Changes in behavior are often the proximate response of animals to human disturbance, with variability in tolerance levels leading some species to exhibit striking shifts in life history,

27 fitness, and/or survival. Thus, elucidating the effects of disturbance on animal behavior, and

28 how this varies among taxonomically similar species with inherently different behaviors and life

29 histories is of value for management and conservation. We evaluated the risk response of three

30 anuran species - southern leopard frog (Lithobates sphenocephalus), Blanchard's cricket frog

31 (Acris blanchardi), and green tree frog (Hyla cinerea) - to determine how differences in

32 microhabitat use (arboreal vs ground-dwelling) and body size (small vs medium) may play a role

33 in response to a potential threat within a human-altered subtropical forest. Each species

34 responded to risk with both flight and freeze behaviors, however behaviors were species- and

35 context-specific. As distance to cover increased, southern leopard frogs increased freezing

36 behavior, green tree frogs decreased freezing behavior, and Blanchard's cricket frogs increased

37 flight response. The propensity of green tree frogs to use the canopy of vegetation as refugia,

38 and the small body size of Blanchard's cricket frogs likely led to greater flight response as

39 distance to cover increased, whereas innate reliance on camouflage among southern leopard

40 frogs may place them at greater risk to landscaping, agricultural, and transportation practices in

41 open terrain. As such, arboreal and small-bodied species may inherently be better suited in

42 human altered-landscapes compared to larger, ground-dwelling species. As land-use change

43 continues to modify habitats, understanding how species respond to changes in their environment

44 continues to be of importance, particularly in ecosystems where human-wildlife interactions are

45 expected to increase in frequency.

46 Keywords: Amphibian; anthropogenic effects; behavioral ecology; edge habitat; human impacts 


\section{Introduction}

Natural and anthropogenic disturbances continue to alter populations across terrestrial,

freshwater, and marine ecosystems (Abatzoglou and Williams 2016; Hughes et al. 2017; Pecl et

al. 2017). Often as a first response to perturbation, changes in behavior precede shifts in life

history, fitness, and survival, which are of considerable interest for conservation in light of many

52

53 imperiled species (Wong and Candolin 2015). Habitat and dietary generalists are inherently more adept at responding to disturbance (Devictor et al. 2008; Hamer and McDonnell 2008; Clavel et al. 2011), however species vary due to interspecific variability in morphology, physiology, and innate behavioral characteristics, regardless of being a specialists or generalist (McKinney 2006; Battisti et al. 2016; Legrand et al. 2017). As such, understanding how perturbations lead to changes in behavior, and how this may vary across taxonomic groups is important for developing a robust ecological paradigm for disturbance ecology (Caruso et al. 2016; Lany et al. 2017; Liu et al. 2017).

A variety of species have adjusted their behavior accordingly in response to a growing human footprint (e.g. Bateman and Fleming 2014; Wong and Candolin 2015; Caruso et al. 2016). For example, many birds and mammals have progressively increased their capacity to use human-altered habitats, and even thrive in some suburban and urban areas (e.g. Chace and Walsh 2006; Bateman and Fleming 2012; Meillère et al. 2015; Luscier 2018). Similarly, other species have significantly increased in population sizes in response to increased food availability and lower predation risk in agricultural areas and parks (e.g. Ganzhorn and Abraham 1991; Naughton-Treves 1998). Not all species, however, have responded positively to anthropogenic impacts. Habitat alterations have been particularly detrimental in many ecosystems, particularly for species that are less mobile and/or have stricter ecological and physiological requirements, 
70 like amphibians (Hamer and McDonnell 2008; Crump 2009; Hughes et al. 2017; Tilman et al.

71 2017). Compared to endotherms, amphibians have limited mobility due to physiological

72 constraints, which results in small home ranges (Wells 2007). Reduced mobility decreases the

73 ability of amphibians to leave altered or degraded habitats, and our understanding of the

74 proximate responses of amphibians (i.e. behavior) to land-use change is critical to inform

75 conservation strategies focused on the long-term persistence of amphibian populations

76 (Pechmann and Wilbur 1994; Gibbs 1998; Houlahan et al. 2000; Crump 2009).

Amphibians are among the most threatened taxonomic groups worldwide, with fungal

infections and habitat degradation serving as leading causes of species declines (Stuart et al. 2004; Wake and Vredenburg 2008; Grant et al. 2016; Lips 2016). Approximately one third of amphibian species are threatened or endangered (IUCN; Collins and Storfer 2003; Stuart et al. 2004), highlighting the urgency of improving our understanding of their behavioral responses to perturbations, and their capacity to keep pace with human actions (Arroyo-Rodriguez et al. 2017; Lourenco et al. 2017; Tilman et al. 2017). Of concern beyond habitat availability is the response of amphibians to human-induced risk in altered habitats, because of the small body size and primary antipredator response of many species - camouflage. Remaining stationary is an effective antipredator response among many amphibians for natural predators that rely on visual cues (Crowshaw 2005; Ioannou and Krause 2009; Stevens and Merilaita 2011; Dodd 2013; Bulbert et al. 2017). However, remaining stationary may be detrimental in response to other

89 risks, such as humans walking or driving vehicles that could lead to non-consumptive mortality

90 (i.e. being stepped on or run over; sensu Andrews and Gibbons 2005; Beebee 2013; Heigl et al. 91 2017). 
Here, we investigate the response of three anuran species with different body sizes, levels

93 of mobility, and microhabitat use patterns - southern leopard frog (Lithobates sphenocephalus),

94 Blanchard's cricket frog (Acris blanchardi), and green tree frog (Hyla cinerea) - to perceived

95 risk at altered edge habitats in a subtropical forest, in order to improve our understanding of the

96 effects of habitat alterations on amphibian response to perturbation. We predicted that in non-

97 vegetated edge habitats, the arboreal species (green tree frog) would exhibit a greater risk

98 response (i.e. flight) than the other species based on its propensity to be found in the canopy of

99 vegetation (Dodd 2013). We also predicted that Blanchard's cricket frogs would exhibit a

100 greater risk response than southern leopard frogs, because of their smaller body size (Dodd

101 2013).

102

103 Materials \& Methods

104 Study site and species

105 Our study took place at Sam Houston State University's Center for Biological Field Studies

$106\left(\mathrm{~N} 30^{\circ} 45^{\prime} \mathrm{W} 95^{\circ} 25^{\prime}\right)$, which is bordered by the Sam Houston National Forest to the south and

107 east, and private ranching and timber holdings to the north and west. Within the Center for

108 Biological Field Studies, pine-hardwood forest, open prairie, old-field succession, and riparian

109 zones are the most abundant habitats (Dent and Lutterschmidt 2001), with amphibian monitoring

110 conducted around ephemeral and permanent ponds.

111 Amphibians within the study area are locally abundant across much of their range and use

112 a variety of altered and unaltered habitats (Pyburn 1958; Dodd et al. 2007; Dodd 2013), making

113 them good model organisms for arboreal species (green tree frog) and semi-aquatic species

114 (southern leopard frogs and Blanchard's cricket frogs) spanning a range of small (Blanchard's 
115 cricket frog) to medium body sizes (southern leopard frog). While all three species breed in

116 lentic aquatic habitats, Blanchard's cricket frogs and green tree frogs breed in permanent aquatic

117 habitats, while southern leopard frogs breed in both temporary and permanent ponds. All three

118 species are primarily generalized invertivores that utilize a sit-and-wait foraging strategy (Dodd

119 2013). However, southern leopard frogs are also capable of consuming small vertebrates (e.g.,

120 fishes, other frogs; Dodd 2013). Southern leopard frogs call year-round in East Texas, while

121 calling activity is concentrated between April and August for both Blanchard's cricket frogs and

122 green tree frogs (Saenz et al. 2006).

123 When immobile, the coloration patterns of Blanchard's cricket frogs make them cryptic

124 on land, however, they are strong jumpers that can quickly change direction when approached

125 (Dodd 2013). Cricket frogs are also known to conceal themselves in vegetation. As such,

126 Blanchard's cricket frogs may respond to an approaching threat initially through crypsis, and

127 then seek vegetative cover. The match between green tree frogs and surrounding vegetation

128 coupled with their reduced diurnal movement serves as the primary anti-predator strategy for

129 green tree frogs when in the canopy of vegetation (Dodd 2013). However, when disturbed,

130 individuals are capable of leaping long distances to evade predators (John-Alder et al. 1988).

131 Southern leopard frogs utilize multiple anti-predator strategies, and can remain motionless and

132 lower their body in a crouching position, or conceal themselves in vegetation (Marchisin and

133 Anderson 1978). The dorsal color and spot patterning enable individuals to match background

134 vegetation (Dodd 2013). Similar to Blanchard's cricket frogs, leopard frogs likely respond first

135 through crypsis, and then seek vegetative cover. Southern leopard frogs also emit a warning

136 scream that functions to startle approaching predators, enabling individuals to escape. 
138

139

140

141

142

143

144

145

146

147

148

149

150 151 (grasses, forbes, trees).

152

153

154

155

156

157

13-1034-3-01.

\section{Data collection}

Four, ca. $1.5 \mathrm{~m}$-wide belt transects (Amo et al. 2006) $250 \mathrm{~m}, 500 \mathrm{~m}, 750 \mathrm{~m}$, and $750 \mathrm{~m}$ long were walked at or after dusk, four times monthly from June-November 2017 to conduct visual surveys $(\mathrm{n}=96)$. Transects were paths and hatchery pond berms where vegetation had been cleared through mowing at the edges of forested habitat. The same belt transects were evaluated for each sampling event, in a randomly selected order, beginning $<0.01$ to 3.78 hours after sunset, depending on selection order (mean $=1.06 \mathrm{hrs}$ after sunset $\pm 0.70 \mathrm{SD})$. Transects were divided into three sections - middle, edge, and boundary - to evaluate how the risk response of frogs to a potential threat (presence of a human) was influenced by proximity to cover/vegetation (Fig. 1). Middle sections were located within the interiors of belt transects, $c a$. $25 \mathrm{~cm}$ from cover with limited vegetation (i.e. low cut grass); edge sections were adjacent to middle section $c a$. 0-25 cm from cover with limited vegetation (i.e. low cut grass); and boundary sections were adjacent to edge sections at the boundary of transects, $c a .25 \mathrm{~cm}$ into vegetation

The same researcher walked slowly on each transect $(<1 \mathrm{~m} / \mathrm{s})$ to detect anurans, and then moved more slowly $(<0.5 \mathrm{~m} / \mathrm{s})$ upon encounters to simulate a threat, but effectively identify anurans (Cooper 2009). Once detected, study taxa were visually identified to species, location on transect was recorded (middle, edge, or boundary), and risk response was recorded stationary (S; i.e. a freeze response), mobile ( $\mathrm{M}$ - moving upon encounter; i.e. a flight response), or mobile-then-stationary (MS - mobile, then stationary after initial movement; i.e. a flight-thenfreeze response). Research was conducted under Sam Houston State University IACUC \#17-02- 
161

162

163

164

165

166

167

168

169

170

171

172

173

174

175

176

177

178

179

180

181

182

\section{Data analysis}

Data were organized by individual animal encounter. A generalized linear model using logistic regression was used to investigate the effects of species and transect section (middle, edge, boundary) on frog risk response. Due to the seasonal variability in environmental conditions within the subtropical study location, and habitat use patterns of the study species (Dodd 2013), monthly variability in frog behavior was considered as a predictor variable in addition to species and transect section. Friedman's test was used to investigate the potential effects of sampling across different months, with significant results $\left(\chi^{2}=35.56, \mathrm{p}<0.01\right)$. Therefore, sampling month was included as a factor in the model. Significant differences were not found across transects $\left(\chi^{2}=1.06, \mathrm{p}=0.90\right)$, thus data were pooled. All main effects (species, section, month) and two-way interactions were included in the model:

$$
H_{i j k l}=\mu+s_{j}+x_{k}+m_{l}+(s x)_{j k}+(s m)_{j l}+(x m)_{k l}+\varepsilon_{i j k l}
$$

Where $s$ is species, $x$ is transect section, $m$ is month, $i$ is the number of sampling events, $j$ is the number of species, $k$ is the number of sections, and $l$ is the number of months. Significance thresholds were corrected for multiple post-hoc comparisons. All analyses were conducted in IBM SPSS 22.

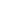

\section{Results}

From June-November 2017, 639 southern leopard frogs, 247 Blanchard's cricket frogs, and 1800 green tree frogs were encountered during 24 nights of sampling across four belt transects $(n=96$ total; Table 1$)$. Leopard frogs and cricket frogs were more abundant in September-November, while green tree frogs were more abundant in July-September (Table 1). 
Among southern leopard frogs, 217 encounters were in the middle of transects (34\%),

184179 were on transect edges (28\%), and 243 were on transect boundaries (38\%). Sixty-six

185 Blanchard's cricket frogs were encountered in the middle of transects $(27 \%)$, 65 were on transect

186 edges (26\%), and 116 were on transect boundaries (47\%). Among green tree frogs, 42

187 encounters were in the middle of transects (2\%), 56 were on transect edges (3\%), and 1702 were

188 on transect boundaries (95\%).

189 The generalized linear model $\left(\chi^{2}=563.88, \mathrm{df}=73, \mathrm{p}<0.01\right)$ indicated that species,

190 transect section, and sampling month, as well as each two-way interaction were significant

191 predictors of frog behavior (Table 2, 1S). Evaluation against an intercept-only model indicated

192 the significance of the model $\left(\chi^{2}=2029.99, \mathrm{df}=33, \mathrm{p}<0.01\right)$. Green tree frogs exhibited

193 greater stationary behavior than Blanchard's cricket frogs, which exhibited more mobile-then-

194 stationary behavior $\left(\chi^{2}=1482.98, \mathrm{p}<0.01\right)$. Green tree frogs also exhibited greater stationary

195 behavior than southern leopard frogs compared to mobile $\left(\chi^{2}=282.21, \mathrm{p}<0.01\right)$ and mobile-

196 then-stationary behavior $\left(\chi^{2}=1325.34, \mathrm{p}<0.01\right)$. Blanchard's cricket frogs exhibited more

197 mobile-then-stationary behavior than southern leopard frogs $\left(\chi^{2}=30.04, p<0.01\right)$.

198 In general, frogs were more mobile at transect edges $\left(\chi^{2}=6.13, p=0.01\right)$ and middles $\left(\chi^{2}\right.$

$199=14.86, \mathrm{p}<0.01)$ than boundaries, however this varied across species $\left(\chi^{2}=92.45, \mathrm{p}<0.01\right)$. As

200 distance from vegetation increased (i.e. boundary to edge to middle), southern leopard frogs

201 increased stationary behavior $\left(\chi^{2}=101.68, \mathrm{p}<0.01\right)$, switching from mobile and mobile-then-

202 stationary behavior at transect boundaries, to mobile-then-stationary and stationary behavior at

203 transect edges, to stationary and mobile-then-stationary behavior in the middle of transects (Fig.

204 2, Table 3). In contrast, Blanchard's cricket frogs exhibited increased mobility from transect 
205 boundary to middle $\left(\chi^{2}=40.05, \mathrm{p}<0.01\right)$, while green tree frogs decreased stationary behavior

206 from transect boundary to middle $\left(\chi^{2}=353.79, p<0.01\right.$; Fig. 2, Table 3$)$.

207 Temporally, green tree frogs and Blanchard's cricket frogs exhibited limited seasonal

208 trends in behavior, while southern leopard frogs exhibited a decrease in stationary behavior from

209 June to November (Fig. 3, Table 4). Southern leopard frogs and Blanchard's cricket frogs were

210 more mobile in June (17\% and 20\%, respectively) and July (23\% and 26\%, respectively)

211 compared to the rest of the sampling period (1\% and 4\%, respectively; Fig. 3). All three species

212 exhibited less mobile-then-stationary behavior than expected at the beginning of the sampling

213 period (June and July), and more mobile-then-stationary behavior than expected at the end of the

214 sampling period (October and November; Table 4).

215

216 Discussion

217 As human impacts continue to alter ecosystems, understanding animal behavior and

218 species abilities to adjust to changing landscapes is of importance for wildlife and habitat

219 management to ensure the maintenance of ecological communities (Becker et al. 2007; Battisti et

220 al. 2016; Legrand et al. 2017; Pecl et al. 2017). Our study shows that the risk response of frogs

221 in an altered forest ecosystem is both species- and context-specific, with some species (i.e.

222 southern leopard frogs) at potentially greater risk to human actions in open terrain than others

223 (i.e. green tree frog). As mobile species, frogs are able to avoid predators and other risks through

224 both flight and camouflage (Marchisin and Anderson 1978). However, the efficacy of risk

225 responses may differ based on characteristics of habitat (open or covered) and risk (visual,

226 olfactory, heat sensing, non-consumptive, natural vs unnatural; Gregory 1979; Wells 2007;

227 Bulbert et al. 2015). Our results suggest that morphology, including the ability to use trees and 
228 other vegetation as refuge, and body size can potentially lead to important differences in the

229 response of animals to risk factors.

230 As predicted, arboreal green tree frogs decreased stationary behavior as the distance to

231 vegetative cover increased, likely due to their propensity to use the canopy of vegetation for

232 refuge (Dodd 2013). Similarly, Blanchard's cricket frogs, a ground-dwelling species, increased

233 mobility as distance to cover increased, which could be attributed to the inherent risk faced by

234 this species based on its small body size (Werner and Gilliam 1984). Supportive of our second

235 hypothesis, southern leopard frogs exhibited the greatest likelihood to freeze in more open terrain

236 (i.e. middle sections of transects), with increased stationary behavior as distance to cover

237 increased. Movement may serve as an indicator to visual predators (Ioannou and Krause 2009),

238 and therefore some ground dwelling frogs may remain stationary, and even flatten themselves

239 against the substrate to avoid detection by predators, such as snakes, birds, and mammals

240 (Marchisin and Anderson 1978). Species-specific differences in risk responses may also be

241 innate - some amphibians actively evade predators (e.g. Tollrian and Harvell 1999), some species

242 engage or scare predators (e.g. Altig 1974), and many remain motionless and use camouflage to

243 blend in to their environments to avoid detection (e.g. Marchisin and Anderson 1978; Stevens

244 and Merilaita 2011).

245 Yet, species with greater tendencies to remain stationary in open but risky habitats may

246 face greater challenges adjusting to human-altered landscapes, with larger-bodied, ground

247 dwelling animals (e.g., leopard frogs) potentially at greater risk of human-induced injury or

248 mortality in unvegetated habitats compared to tree dwelling species (Beebee 2013; Sosa and

249 Schalk 2016). Camouflage is a primary antipredator response of many frogs (Marchisin and

250 Anderson 1978), and all three study species exhibited stationary behavior $(98 \%, 30 \%$, and $13 \%$, 
251 respectively for green tree frogs, southern leopard frogs, and Blanchard's cricket frogs), overall

252 with more frequent freeze responses in more vegetated transect sections (boundary, edge). In

253 terrestrial habitats, species at risk may be more vigilant as terrain becomes less protected by

254 vegetation or landscape features, and flee into more covered habitat when risk exceeds a

255 threshold in open habitats (Edut and Eilam 2003; Stankowich 2008). Green tree frogs and

256 Blanchard's cricket frogs followed this model, while southern leopard frogs did not, exhibiting

257 an inverse relationship between distance to cover and flight (Takada et al. 2018).

258 Across human-altered ecosystems, some innate behaviors remain beneficial, and the

259 plasticity of other behaviors make them more advantageous in disturbed ecosystems (Chace and

260 Walsh 2006; McKinney 2006; McCleery 2009). For example, the scavenging nature of some

261 predators increases their foraging efficiency in urban and suburban environments where

262 discarded human food is nutritionally beneficial and widely available, reducing energetic costs

263 (e.g. Fedriani et al. 2001; Merkle et al. 2013). Similarly, human structures can be readily

264 incorporated and utilized by species that rely on camouflage for protection (Merilaita 2003;

265 Banos-Villaba et al. 2018). However, camouflage in ecosystems used by humans is likely most

266 effective for species that blend-in with elevated structure, both natural and man-made. Indeed,

267 camouflage and freeze responses among ground-dwelling species likely provide little protection

268 from agricultural, landscaping, and transportation practices, each presenting lethal risk

269 (Trombulak and Frissell 2000; Kirk et al. 2001; Carvalho et al. 2017). For many species,

270 humans present unnatural conditions and perturbations that heighten risk (Cushman 2006; Wong

271 and Candolin 2015; Li et al. 2017). Yet while camouflage may be the primary risk response of

272 many frogs, this behavior is apparently not ubiquitous among all species, enabling some taxa to

273 thrive in urban and suburban environments (Rubbo and Kiesecker 2005; Hamer and McDonnell 
274 2008; Scheffers and Paszkowski 2012). Identifying species at greater risk and greater

275 adaptability is of importance moving forward in urban and disturbance ecology, as well as

276 conservation, in which identifying general behavioral patterns may be of great value (Lima and

277 Dill 1990; Wong and Candolin 2015; Battisti et al. 2016). Our data suggest that arboreal and

278 small-bodied species may be more able to adjust to human impacts than larger-bodied, ground-

279 dwelling species, however more refined study designs are needed to test this hypothesis.

280

281 Caveats

282 In light of the observed behavioral patterns and the extensive use of stationary/freeze

283 responses by all three study species, observations may have been biased based on the

284 researcher's ability to detect immobile frogs near or in vegetation (boundary and edge habitats).

285 Yet, substantially more individuals were detected along the boundaries of transect $(n=2062)$

286 compared to transect edges $(\mathrm{n}=300)$ and middles $(\mathrm{n}=325)$. Thus, detection bias was an

287 unlikely factor in shaping the observed trends, and was uniform across all sampling events,

288 because the same observer collected all sampling data.

289 Seasonal variability in environmental conditions and reproduction often shape animal

290 behavior in subtropical latitudes (e.g. Matich et al. 2017), and frogs exhibited monthly

291 differences in behavior. Yet, temporal trends in behavior were limited among the study species.

292 Frogs became more mobile from Summer to Autumn, which could be due to decreased

293 vegetation on transects as air temperature decreased, reducing the effectiveness of camouflage,

294 and/or differences in ground and air temperatures, food availability, or breeding cycles (Saenz et

295 al. 2006; Wells 2007). Seasonal variability in predation risk could also lead to seasonal patterns 
296 in activity levels and behavior of frogs (Lode 2000; Sperry et al. 2008), however more controlled

297 experiments are needed to test these hypotheses.

298

299 Conclusions

$300 \quad$ Habitat degradation continues to pose important conservation concerns across all

301 ecosystems, including forests harvested for timber and converted to agricultural and ranch lands

302 (Arroyo-Rodriguez et al. 2017; Lourenco et al. 2017; Tilman et al. 2017). Amphibians rely on

303 tropical, subtropical, and temperate forests for habitat and food resources, and in strongholds

304 where diseases have not infected populations, habitat management and conservation is of great

305 importance (Stuart et al. 2004; Grant et al. 2016). Our results suggest that differences in distance

306 to cover, habitat use patterns, and body size may affect frog behavior, with a greater propensity

307 for flight responses to risk by arboreal frogs in open terrain (green tree frogs), and a greater

308 propensity for freeze responses to risk by larger, ground-dwelling frogs (southern leopard frogs).

309 With growing perturbations to many forested regions, these context-specific behaviors are of

310 important consideration for future conservation and management in human-altered systems.

311

312 Acknowledgments

313 We thank the Center for Biological Field Studies and Alan Byboth for providing logistical

314 support during data collection, and the many volunteers that helped survey frogs, including Kaya

315 Moore, Demtri Payblas, Monica Anderson, and Kayla Hankins. We also thank the Texas

316 Research Institute for Environmental Studies for providing logistical support in preparation of

317 the manuscript. 


\section{References}

320 Abatzoglou, J.T. \& Williams, A.P. (2016) Impact of anthropogenic climate change on wildfire across western US forests. PNAS 113, 11770-11775.

322

323

324

326

Altig, R. (1974) Defense behavior in Rana areolata and Hyla avivoca. Quar. J. Florida. Acad. Sci. 35, 212-216.

Amo, L., Lopez, P., \& Martin, J. (2006). Nature-based tourism as a form of predation risk affects body condition and health status of Podarcis muralis lizards. Biol. Conserv. 131, 402409.

Andrews, K.M. \& Gibbons, J.W. (2005) How do highways influence snake movement? Behavioral responses to roads and vehicles. Copeia 2005, 772-782.

Arroyo-Rodriguez, V., Melo, F.P.L., Martinez-Ramos, M., Bongers, F., Chazdon, R.L., Meave, J.A., Norden, N., Santos, B.A., Leal, I.R. \& Tabarelli, M. (2017) Multiple successional pathways in human-modified tropical landscapes: new insights from forest succession, forest fragmentation and landscape ecology research. Biol. Rev. 92, 326-340.

Banos-Villabla, A., Quevedo, D.P., \& Edelaar, P. (2018). Positioning behavior according to individual color variation improves camouflage in novel habitats. Behav. Ecol. 29, 404410.

Bateman, P. W., \& Fleming, P. A. (2012). Big city life: carnivores in urban environments. $J$. Zool. 287, 1-23.

Bateman, P. W., \& Fleming, P. A. (2014). Does human pedestrian behaviour influence risk assessment in a successful mammal urban adapter? J. Zool, 294, 93-98.

Battisti, C., Poeta, G. \& Fanelli, G. (2016) An introduction to disturbance ecology. A road map for wildlife management and conservation. Springer. P. 178. 
342 Becker, C.G., Fonseca, C.R., Haddad, C.F.B., Batista, R.F. \& Prado, P.I. (2007) Habitat split and 343 the global decline of amphibians. Science 318, 1775-1777.

344 Beebee, T.J.C. (2013) Effect of road mortality and mitigation measures of amphibian

345

346

347

348

349

350

351

352

353

354

355

356

357

358

359

360

361

362

363

364 populations. Conserv. Biol. 27, 657-668

Bulbert, M.W., Page, R.A. \& Bernal, X.E. (2015) Danger comes from all fronts: predatordependent escape tactics of Túngara frogs. PLoS ONE 10, e0120546.

Bulbert, M.W., White, T.E., Saporito, R.A. \& Kraus, F. (2017) Ontogenetic colour change in Oreophryne ezra (Anura: Microhylidae) reflects an unusual shift from conspicuousness to crypsis but not in toxicity. Biol. J. Linn. Soc. 12, 12-20.

Caruso, N., Lucherini, M., Fortin, D. \& Casanave, E.B. (2016) Species-specific responses of carnivores to human-induced landscape changes in central Argentina. PLoS ONE 11, e0150488.

Carvalho F., Santos S.M., Mira A., \& Lourenço R. (2017) Methods to Monitor and Mitigate Wildlife Mortality in Railways. In: Borda-de-Água L., Barrientos R., Beja P., Pereira H. (eds) Railway Ecology. Springer. P. 23-42.

Chace, J.F. \& Walsh, J.J. (2006) Urban effects on native avifauna: a review. Landsc. Urban Plan. 74, 46-69.

Clavel, J., Julliard, R., \& Devictor, V. (2011). Worldwide decline of specialist species: toward a global functional homogenization? Frontiers Ecol. Environ. 9, 222-228

Collins, J.P. \& Storfer, A. (2003) Global amphibian declines: sorting the hypotheses. Diver. Distrib. 9, 89-98.

Cooper, W.E. Jr. (2009) Fleeing and hiding under simultaneous risks and costs. Behav. Ecol. 20, 665-671. 
365 Crowshaw, D.A. (2005) Cryptic behavior is independent of dorsal color polymorphism in

366 juvenile northern leopard frogs (Rana pipiens). J. Hepr. 29, 125-129.

367 Crump, M.L. (2009) Amphibian diversity and life history. Amphibian Ecology and

368 Conservation. A Handbook of Techniques, 3-20.

369 Cushman, S.A. (2006) Effects of habitat loss and fragmentation on amphibians: a review and prospectus. Biol. Conserv. 128, 231-240.

371

372

373

374

375

376

377

378

379

380

381

382

383

384

385

386

Dent, L. \& Lutterschmidt, W.I. (2001) The ichthyofauna of Harmon and Wynne Creeks sampled within the Center for Biological Field Studies, Walker County, Texas. Texas. J. Sci. 53, $139-146$.

Devictor, V., Julliard, R., \& Jiguet, F. (2008). Distribution of specialist and generalist species along spatial gradients of habitat disturbance and fragmentation. Oikos 117, 507-514.

Dodd, C.K. (2013) Frogs of the United States and Canada, 2-vol. set (Vol. 1\&2). JHU Press.

Dodd, C.K. Jr., Barichivich, W.J., Johnson, S.A. \& Staiger, J.S. (2007) Changes in a northwestern Florida gulf coast herpetofaunal community over a 28 -y period. Am. Mid. Nat. 158, 29-48.

Edut, S. \& Eilam, D. (2003). Rodents in open space adjust their behavioral response to the different risk levels during barn-owl attack. BMC Ecology 3, 10.

Fedriani, J.M., Fuller, T.K., \& Sauvajot, R.M. (2001). Does availability of anthropogenic food enhance densities of omnivorous mammals? An example with coyotes in southern California. Ecography 24, 325-331.

Ganzhorn, J. U. \& J.-P. Abraham. (1991). Possible role of plantations for lemur conservation in Madagascar: food for folivorous species. Folia Primatologica 56, 171-176. 
387 Gibbs, J. P. (1998). Genetic structure of redback salamander Plethodon cinereus populations in 388 continuous and fragmented forests. Biol. Conserv. 86, 77-81.

389 Grant, E.H.C., Miller, D.A., Schmidt, B.R., Adams, M.J., Amburgey, S.M., Chambert, T., et al. 390 (2016) Quantitative evidence for the effects of multiple drivers on continental-scale $391 \quad$ amphibian declines. Sci. Rep. 6, 25625.

392 Gregory, P.T. (1979) Avoidance behavior of the red-legged frog (Rana aurora). Herpetologica 393 35, $175-184$.

394 Hamer, A.J., \& McDonnell, M.J. (2008) Amphibian ecology and conservation in the urbanizing 395 world: A review. Biol. Conserv. 10, 2432-2449.

396 Heigl, F., Horvath, K., Laaha, G. \& Zaller, J.G. (2017) Amphibian and reptile road-kills on tertiary roads in relation to landscape structure: using a citizen science approach with open-access land cover data. BMC Ecology 17, 24.

Houlahan, J.E., Findlay, C.S., Schmidt, B.R., Meyer, A.H., \& Kuzmin, S.L. (2000) Quantitative 400 evidence for global amphibian population declines. Nature 404, 752-755.

401

402

403

404

405

406

407

408

409

Hughes, T.P., Barnes, M.L., Bellwood, D.R., Cinner, J.E., Cumming, G.S., Jackson, J.B.C., Kleypas, J., van de Leemput, I.A., Lough, J.M., Morrison, T.H., et al. (2017) Coral reefs in the Anthropocene. Nature 546, 82-90.

Ioannou, C.C. \& Krause, J. (2009) Interactions between background matching and motion during visual detection can explain why cryptic animals keep still. Biol. Lett. 5, 191-193.

John-Alder, H.B., Morin, P.J. \& Lawler, S. (1988) Thermal physiology, phenology, and distribution of tree frogs. Am. Nat. 132, 506-520.

Kirk, D. A., Lindsay, K. E., \& Brook, R. W. (2011). Risk of agricultural practices and habitat change to farmland birds. Avian Conserv Ecol 6, 5. 
410 Lany, N.K., Zarnetske, P.L., Gouhier, T.C. \& Menge, B.A. (2017) Incorporating context dependency of species interactions in species distribution models. Int. Compar. Biol. 57,

412 $159-167$.

413 Legrand, D., Cote, J., Fronhofer, E.A., Holt, R.D., Ronce, O., Schtickzelle, N., Travis, J.M.J. \& 414 Clobert, J. (2017) Eco-evolutionary dynamics in fragmented landscapes. Ecography 40, $9-25$.

Li, D., Liu, Y., Sun, X., Lloyd, H., Zhu, S., Zhang, S., Wan, D., \& Zhang, Z. (2017) Habitatdependent changes in vigilance behavior of Red-crowned Crane influenced by wildlife tourism. Sci. Rep. 7, 16614.

Lima, S. L. \& Dill, L. M. (1990). Behavioral decisions made under the risk of predation: a review and prospectus. Can. J. Zool. 68, 619-640.

Lips, K.R. (2016) Overview of chytrid emergence and impacts on amphibians. Phil. Trans.

423

424

425

426

427

428

431 Royal. Soc. B 371, 20150465.

Liu, X.P., Liang, X., Li, X., Xu, X.C., Ou, J.P., Chen, Y.M., Li, S.Y., Wang, S.J. \& Pei, F.S. (2017) A future land use simulation model (FLUS) for simulating multiple land use scenarios by coupling human and natural effects. Landscape Urban Plan. 168, 94-116.

Lode, T. (2000) Functional response and area-restricted search in a predator: seasonal exploitation of anurans by the European polecat, Mustela putorius. Aust. Ecol. 25, 223231.

Lourenco, A., Alvarex, D., Wang, I.J. \& Velo-Anton, G. (2017) Trapped within the city: integrating demography, time since isolation and population-specific traits to assess the genetic effects of urbanization. Molec. Ecol. 6, 1498-1514. 
432 Luscier, J.D. (2018). Effects of urbanization on great-tailed grackle habitat use and nest success 433 in Sherman, Texas. Urban Nat. 15, 1-14.

434 Marchisin, A. \& Anderson, J.D. (1978) Strategies employed by frogs and toads (Amphibia, 435 Anura) to avoid predation by snakes (Reptilia, Serpentes). J. Herp. 12, 151-155.

436 Matich, P., Ault, J. S., Boucek, R. E., Bryan, D. R., Gastrich, K. R., Harvey, C. L., ... \&

437 Rosenblatt, A. E. (2017). Ecological niche partitioning within a large predator guild in a 438 nutrient-limited estuary. Limnol. Oceanog. 62, 934-953.

439 McCleery, R.A. (2009). Changes in fox squirrel anti-predator behaviors across the urban-rural $440 \quad$ gradient. Landsc. Ecol. 24, 483.

441 McKinney, M.L. (2006) Urbanization as a major cause of biotic homogenization. Biol. Conserv. $127,247-260$.

443 Meillère, A., Brischoux, F., Parenteau, C., \& Angelier, F. (2015). Influence of urbanization on 444 body size, condition, and physiology in an urban exploiter: a multi-component $445 \quad$ approach. PloS one 10, e0135685.

446 Merkle, J.A., Robinson, H.S., Krausman, P.R., \& Alaback, P. (2013) Food availability and 447 foraging near human developments by black bears. J. Mamm. 94, 378-385.

448 Merilaita, S. (2003). Visual background complexity facilitates the evolution of camouflage. $449 \quad$ Evolution, 57: 1248-1254.

450 Naughton-Treves, L. (1998). Predicting patterns of crop damage by wildlife around Kibale 451 National Park, Uganda. Conserv. Biol. 12, 156-168.

452 Pechmann, J.H.K. \& Wilbur, H.M. (1994) Putting declining amphibian populations in 453 perspective - natural fluctuations and human impacts. Herpetologica 50, 65-84. 
454 Pecl, G.T., Araujo, M.B., Bell, J.D., Blanchard, J., Bonebrake, T.C., Chen, I.C., Clark, T.D., et

455

456

457

458

459

460

461

462

463

464

465

466

467

468

469

470

471

472

473

474

al. (2017) Biodiversity redistribution under climate change: impacts on ecosystems and human well-being. Science 355, eaai9214.

Pyburn, W.F. (1958) Size and movements of a local population of cricket frogs (Acris crepitans). Texas. J. Sci. 10, 325-342.

Rubbo, M.J. \& Kiesecker, J.M. (2005). Amphibian breeding distribution in an urbanized landscape. Conserv. Biol. 19, 504-511.

Saenz, D., Fitzgerald, L.A., Baum, K.A. \& Conner, R.N. (2006) Abiotic correlates of anuran calling phenology: the importance of rain, temperature, and season. Herp. Monogr. 20, $64-82$.

Scheffers, B. R., \& Paszkowski, C. A. (2012). The effects of urbanization on North American amphibian species: identifying new directions for urban conservation. Urban Ecosys. 15, 133-147.

Sosa, R. \& Schalk, C.M. (2016) Seasonal activity and species habitat guilds influence road-kill patterns of Neotropical snakes. Trop. Conserv. Sci. 9, 1-12.

Sperry, J.H., Peak, R.G., Cimprich, D.A., \& Weatherhead, P.J. (2008) Snake activity affects seasonal variation in nest predation risk for birds. J. Avian. Biol. 39, 379-383.

Stankowich, T. (2008) Ungulate flight responses to human disturbance: A review and metaanalysis. Biol. Conserv. 141, 2159-2173.

Stevens, M. \& Merilaita, S. (2011) Animal Camouflage. Mechanisms and Function. Cambridge University Press. P. 357.

Peer) reviewing PDF | (2018:11:32865:1:0:NEW 22 Mar 2019) 
475 Stuart, S.N., Chanson, J.S., Cox, N.A., Young, B.E., Rodrigues, A.S., Fischman, D.L. \& Waller, 476 R.W. (2004) Status and trends of amphibian declines and extinctions worldwide. Science

477 478

480

481

482 483 484 485 486

487 488 489 490 491 492 493 494 306, 1783-1786.

Takada, H., Nakamura, K., Takatsuki, S., \& Minami, M. (2018). Freezing behavior of the Japanese serow (Capricornis crispus) in relation to habitat and group size. Mamm. Res. 63, 107-112.

Tilman, D., Clark, M., Williams, D.R., Kimmel, K., Polasky, S. \& Packer, C. (2017) Future threats to biodiversity and pathways to their prevention. Nature 546, 73-81.

Tollrian, R. \& Harvell, C.D. (eds.) (1999). The ecology and evolution of inducible defenses. Princeton University Press

Trombulak, S.C. \& Frissell, C.A. (2000). Review of ecological effects of roads on terrestrial and aquatic communities. Conserv. Biol. 14, 18-30.

Wake, D.B. \& Vredenburg, V.T. (2008) Are we in the midst of the sixth mass extinction? A view from the world of amphibians. PNAS 105, 11466-11473.

Wells, K.D. (2007) The ecology and behavior of amphibians. Chicago: The University of Chicago Press

Werner, E.E., \& Gilliam, J.F. (1984) The ontogenetic niche and species interactions in sizestructured populations. An. Rev. Ecol. System. 15, 393-425

Wong, B.B.M. \& Candolin, U. (2015) Behavioral responses to changing environments. Behav. Ecol. 26, 665-673. 


\section{Table $\mathbf{1}$ (on next page)}

Sample sizes of study species observed during sampling period.

Sample sizes of study species observed during sampling period from June - November 2017 . 
1 Table 1: Sample sizes of study species observed during sampling period from June - November 2017.

3

\begin{tabular}{llr} 
Species & Month & N \\
\hline L. sphenocephalus & June & 54 \\
& July & 46 \\
& August & 36 \\
& September & 170 \\
& October & 163 \\
& November & 170
\end{tabular}

$\begin{array}{llr}\text { A. blanchardi } & \text { June } & 18 \\ & \text { July } & 13 \\ & \text { August } & 39 \\ \text { September } & 45 \\ & \text { October } & 30 \\ & \text { November } & 102 \\ & & \\ \text { H. cinerea } & \text { June } & 166 \\ & \text { July } & 777 \\ & \text { August } & 340 \\ & \text { September } & 268 \\ & \text { October } & 151 \\ & \text { November } & 98\end{array}$

4 


\section{Table 2 (on next page)}

Test statistics for the generalized linear model .

Test statistics for the generalized linear model investigating the effects of species, location on transection (i.e. section), and sampling month on the risk response of $A$. blanchardi, $H$. cinerea, and L. sphenocephalus. 
1 Table 2: Test statistics for the generalized linear model investigating the effects of species,

2 location on transection (i.e. section), and sampling month on the risk response of $A$. blanchardi, 3 H. cinerea, and L. sphenocephalus.

4

\begin{tabular}{lccc} 
Factor & $\chi^{2}$ & df & p-value \\
\hline Species & 139.59 & 2 & $<0.01$ \\
Transect section & 10.71 & 2 & $<0.01$ \\
Month & 24.57 & 5 & $<0.01$ \\
Species*Section & 140.64 & 4 & $<0.01$ \\
Species*Month & 31.76 & 10 & $<0.01$ \\
Section*Month & 33.06 & 10 & $<0.01$
\end{tabular}

5 


\section{Table 3(on next page)}

Post hoc results for chi squared test of location-specific differences in risk behavior.

Post hoc results for chi squared test of location-specific differences in risk behavior. $M$ indicates mobile behavior, MS indicates mobile-then-stationary behavior, $\mathrm{S}$ indicates stationary behavior, and ND indicates no difference between behaviors. 
1 Table 3: Post hoc results for chi squared test of location-specific differences in risk behavior. M

2 indicates mobile behavior, MS indicates mobile-then-stationary behavior, $\mathrm{S}$ indicates stationary

3 behavior, and ND indicates no difference between behaviors.

\begin{tabular}{lccc} 
& \multicolumn{1}{c}{ Boundary } & Edge & Middle \\
\cline { 2 - 4 } L. sphenocephalus & $\mathrm{M} \& \mathrm{MS}>\mathrm{S}$ & $\mathrm{MS} \& \mathrm{~S}>\mathrm{M}$ & $\mathrm{S} \& \mathrm{MS}>\mathrm{M}$ \\
A. blanchardi & $\mathrm{MS}>\mathrm{S}>\mathrm{M}$ & $\mathrm{MS}>\mathrm{M} \& \mathrm{~S}$ & $\mathrm{M} \& \mathrm{MS}>\mathrm{S}$ \\
H. cinerea & $\mathrm{S}>\mathrm{MS}>\mathrm{M}$ & $\mathrm{S}>\mathrm{M} \& \mathrm{MS}$ & $\mathrm{ND}$
\end{tabular}

4 


\section{Table 4 (on next page)}

Post hoc results for chi squared test of month-specific differences in risk behavior.

Post hoc results for chi squared test of month-specific differences in risk behavior. $M$ indicates mobile behavior, MS indicates mobile-then-stationary behavior, and S indicates stationary behavior. A plus (+) indicates a behavior exhibited more frequently than expected, a minus (-) indicates a behavior exhibited less frequently than expected, and ND indicates no difference between behaviors. 
1 Table 4: Post hoc results for chi squared test of month-specific differences in risk behavior. M

2 indicates mobile behavior, MS indicates mobile-then-stationary behavior, and $\mathrm{S}$ indicates

3 stationary behavior. A plus ( + ) indicates a behavior exhibited more frequently than expected, a

4 minus (-) indicates a behavior exhibited less frequently than expected, and ND indicates no

5 difference between behaviors.

6

\begin{tabular}{lcccccc} 
& Jun & Jul & Aug & Sep & Oct & Nov \\
\cline { 2 - 6 } L. sphenocephalus & $-\mathrm{MS}$ & $-\mathrm{MS},+\mathrm{M}$ & $-\mathrm{MS},-\mathrm{M}$ & $\mathrm{ND}$ & $+\mathrm{MS}$ & $+\mathrm{MS}$ \\
A. blanchardi & $-\mathrm{MS}$ & $+\mathrm{M}$ & $\mathrm{ND}$ & $+\mathrm{MS}$ & $+\mathrm{MS}$ & $+\mathrm{MS}$ \\
H. cinerea & $\mathrm{ND}$ & $-\mathrm{MS}$ & $\mathrm{ND}$ & $\mathrm{ND}$ & $+\mathrm{MS}$ & $+\mathrm{MS}$
\end{tabular}


Figure 1 (on next page)

Transect sections used to evaluate how the risk response of frogs was influenced by proximity to cover.

Transect sections used to evaluate how the risk response of frogs was influenced by proximity to cover. Middle sections were located ca. $25 \mathrm{~cm}$ from cover; edge sections were ca. 0-25 cm from cover; and boundary sections were adjacent to edge sections at the boundary of transects, ca. $25 \mathrm{~cm}$ into vegetation. In the figure, black frogs are in boundary sections, light gray frogs are in edge sections, and dark gray frogs are in the middle section. 
Figure 1: Transect sections used to evaluate how the risk response of frogs was influenced by proximity to cover. Middle sections were located $c a .25 \mathrm{~cm}$ from cover; edge sections were $c a$. 0-25 cm from cover; and boundary sections were adjacent to edge sections at the boundary of transects, $c a .25 \mathrm{~cm}$ into vegetation. In the figure, black frogs are in boundary sections, light gray frogs are in edge sections, and dark gray frogs are in the middle section.

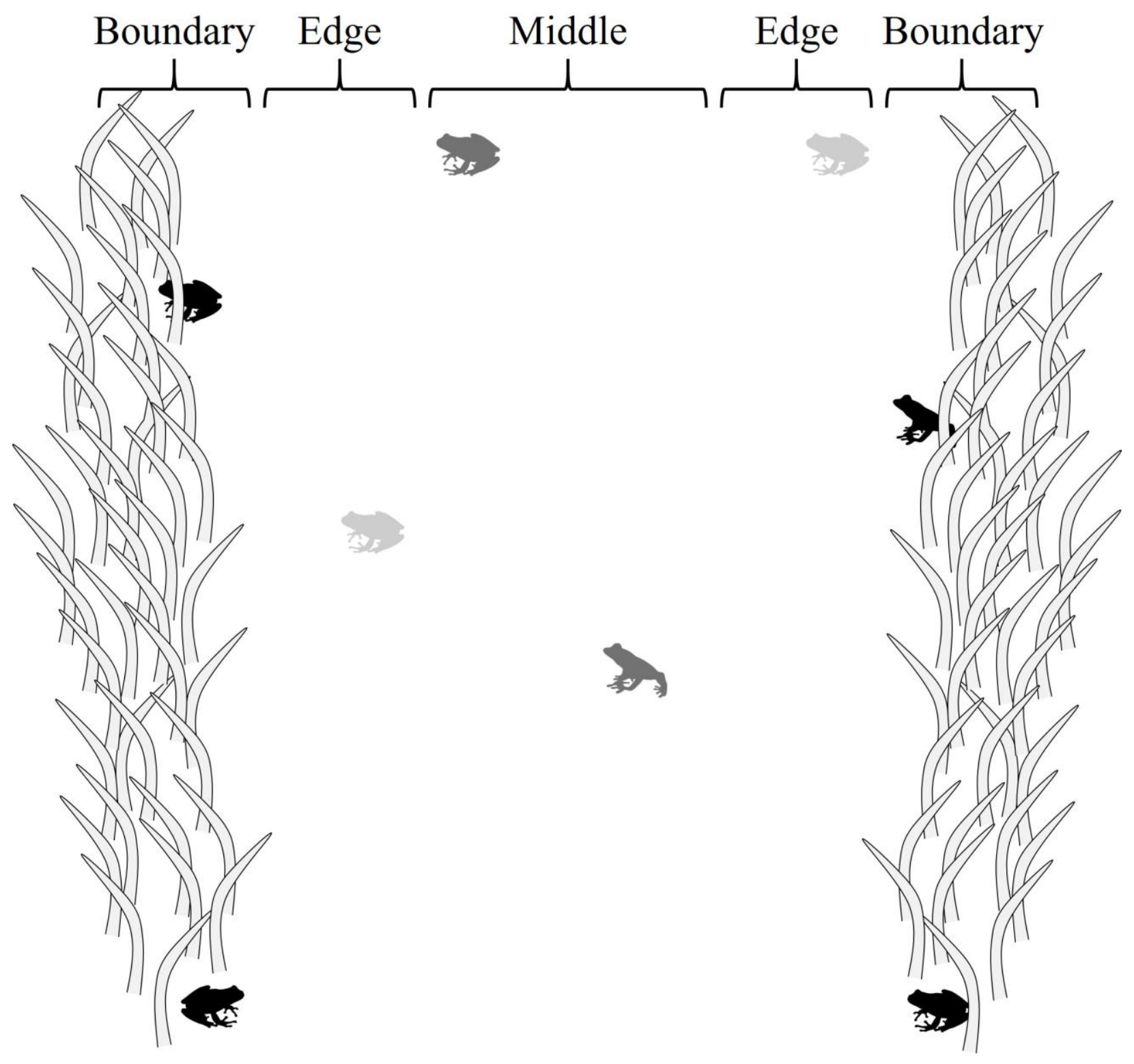


Figure 2 (on next page)

Spatial patterns in frog behavior

Proportion of encounters among study species in transect sections that remained stationary (S; light gray), mobile-then-stationary (MS; dark gray), and mobile (M; black) among southern leopard frogs (L. sphenocephalus), Blanchard's cricket frogs (A. blanchardi), and green tree frogs $(H$. cinerea). 
Figure 2: Proportion of encounters among study species in transect sections that remained stationary (S; light gray), mobile-then-stationary (MS; dark gray), and mobile (M; black) among southern leopard frogs (L. sphenocephalus), Blanchard's cricket frogs (A. blanchardi), and green tree frogs (H. cinerea).

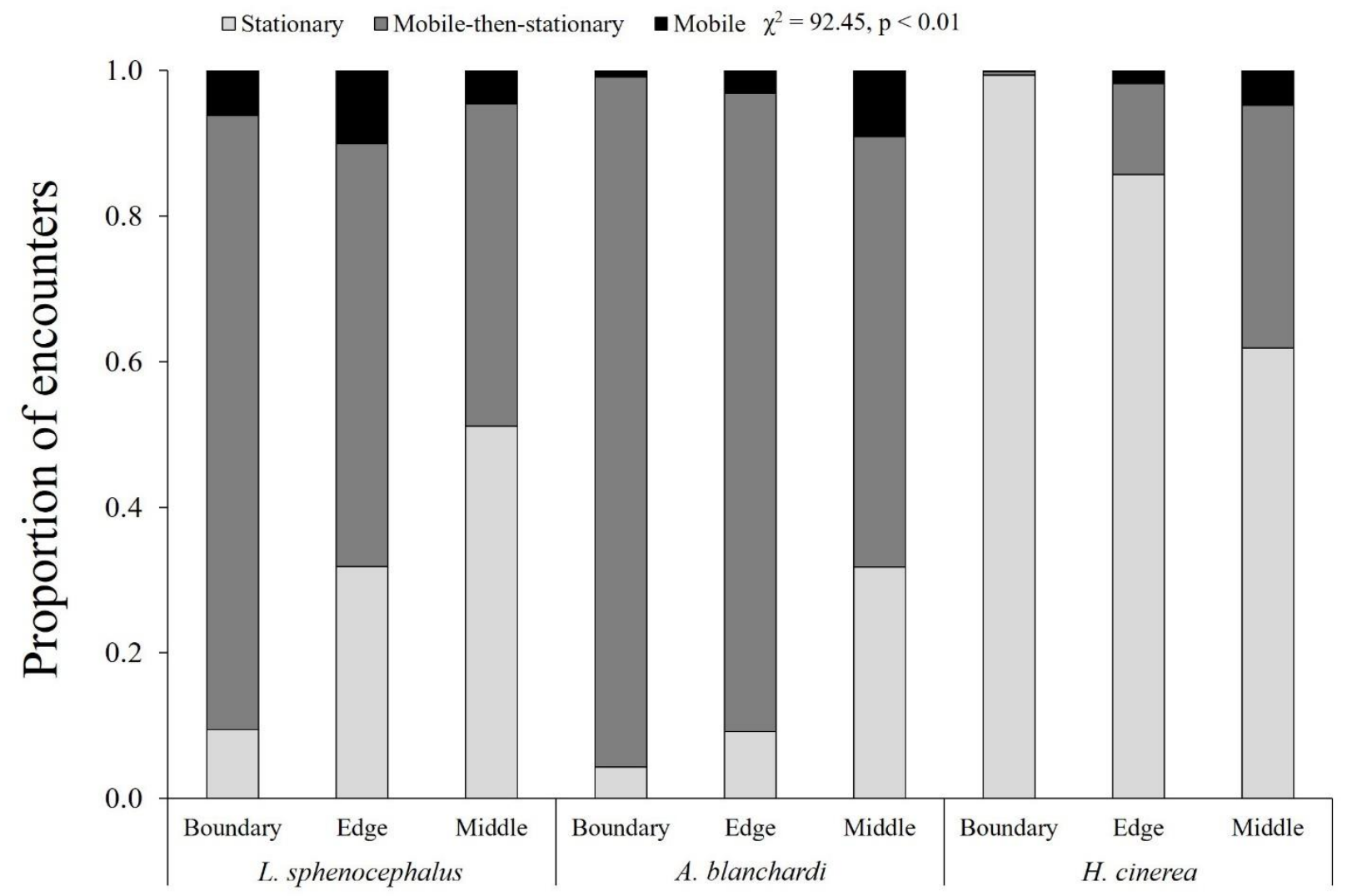


Figure 3 (on next page)

Monthly patterns in frog behavior

Monthly patterns in behavior [stationary (S; light gray), mobile-then-stationary (MS; dark gray), and mobile (M; black)] among southern leopard frogs (L. sphenocephalus), Blanchard's cricket frogs (A. blanchardi), and green tree frogs (H. cinerea). 
Figure 3: Monthly patterns in behavior [stationary (S; light gray), mobile-then-stationary (MS; dark gray), and mobile (M; black)] among southern leopard frogs (L. sphenocephalus), Blanchard's cricket frogs (A. blanchardi), and green tree frogs (H. cinerea).

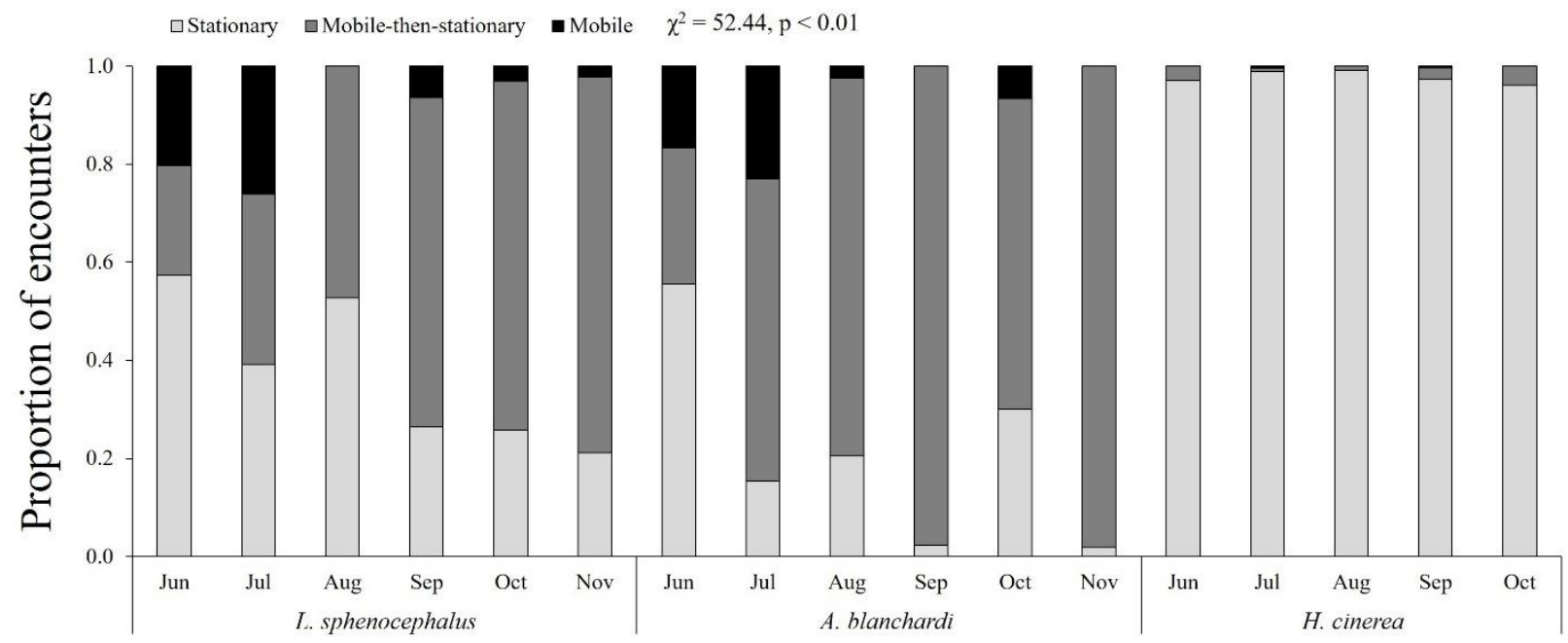

